\title{
A METAFÍSICA DA SAUDADE
}

\author{
Maria Celeste Natário \\ Universidade do Porto \\ mcnatario@gmail.com
}

\section{Resumen}

En este trabajo abordamos algunos de los aspectos más relevantes del pensamiento del poeta y filósofo Teixeira de Pascoaes acerca de la Saudade, destacando su dimensión más "metafísica".

Palabras clave: Teixeira de Pascoaes, Saudade, Metafísica.

\section{Abstract}

In this paper, we deal with some of the most striking dimensions of the poet and philosopher Teixeira de Pascoaes' thought on the subject of Saudade. We point out its more "metaphysical" aspects.

Keywords: Teixeira de Pascoaes, Saudade, Metaphysics.

"o mundo é o homem feito de terra e céu, de física e metafísica e de outros elementos ignorados, não do nosso ser, mas da nossa inteligência"

Teixeira de Pascoaes ${ }^{1}$

“por metafísica designa-se não só e apenas o que está para além do físico, mas antes e primordialmente o que lhe é íntimo e nele se supõe"

José Marinho²

Recibido: 17/03/2011. Aceptado: 13/04/2011.

${ }^{1}$ O Homem Universal e outros escritos, fixação do texto, pref. e notas de Pinharanda Gomes, Lisboa, Assírio \& Alvim, 1993, p. 54.

${ }^{2}$ Cf. O Pensamento Filosófico de Leonardo Coimbra, Porto, Figuerinhas, p. 133. 
A revelação do sentido mais profundo da existência humana e do mundo foi durante séculos e séculos a missão da metafísica. Isso alterou-se em parte no último século, com o papel que, entretanto, a ciência foi assumindo e, cumulativamente, com o progressivo prestígio, ainda sob o influxo da crítica kantiana, das filosofias empíricas. De tal modo isso foi assim que hoje, em geral, o pensamento humano se tornou, mesmo não ignorando as múltiplas excepções, anti-metafísico. Essa foi, de resto, a "sentença" de Martin Heidegger, provavelmente o filósofo mais decisivo do último século, ter decretado o "fim da metafísica", mas não, obviamente, da filosofia.

Decerto, a filosofia hoje como ontem não pode ser indiferente à crítica kantiana da metafísica -apesar dos Prolegómenos a toda a metafísica futura, em que se deixa a porta aberta para uma "metafísica moral"-, e a tudo o que desta, directa ou indirectamente, decorreu. Mas, ao mesmo tempo, importa, a nosso ver, regressar à filosofia grega, onde o desvelamento da natureza primordial do cosmos, partindo da Natureza e nela se inspirando, procuram na physis — primeiro pela sua contemplação, mas também pelo desejo e necessidade- uma resposta ou respostas capazes não só de responder à pergunta pela origem mas também algo que explicasse a dualidade, assim permitindo a unidade e harmonia. E foi esta sabedoria que afinal se tornou para nós indispensável e é parte do caminho ou, melhor, do seu começo, que se tornou longo mas é também interminável, por ser um caminho sem fim.

Depois dos pré-socráticos, uma das figuras que importa decerto referir é, para além de Platão, Aristóteles. Nele poderemos reencontrar uma concepção de filosofia que se caracteriza, desde logo, pela sua integralidade. Nele, a filosofia é, simultânea e indissoluvelmente, conhecimento do ser e realização do humano, ao mesmo tempo que nele também poderemos encontrar, como já foi também salientado por Heidegger, uma noção de "física”, physis, que transcende a posterior oposição entre física e metafísica.

Mas o nosso horizonte neste ensaio é, acima de tudo, o pensar e sentir de Teixeira de Pascoaes, o poeta da comunhão e celebração da natureza e da vida, o poeta que penetra na essência da realidade, tornando-se interior a ela mesma, e cuja expressão é a identificação com o cosmos, a palavra que é meio e simultaneamente parte da substância, da sua obra e da sua concepção poético-filosófica. Pensar e sentir radicados na montanha, na sua luz e nas suas sombras, sendo aí que os seus versos, a sua prosa, a sua pintura, terão que ser compreendidos. É aí, à luz de uma inspiração às vezes dolorosa e sempre ou quase sempre divina, que se enraíza a verdade e a solidez da sua arte. De uma arte feita de versos e prosas cujas notas musicais são também o sinal de uma poesia de afirmação profético-mística. 
$\mathrm{Na}$ sua paisagem de matéria viva, exaltada e humilde, todos os recortes são densos, mesmo que às vezes os montes sejam arredondados e amenos. De modulações suspensas é o seu sombreado, que não resulta de estáticas sombras, mas sim de uma vivência do que pode chamar-se uma herética religiosidade, de intuições e impulsos, cuja densidade de profundos sulcos nos conduz a uma paisagem que é a do Poeta, e, por isso, por ele transformada.

A direcção e o sentido da sua cósmica relação, exaltada e apaixonada, visam, no começo como no fim, a harmonia. Naturalmente espontânea é a sublimidade e o magnetismo da sua arte, da sua filosofia da natureza, que a nosso ver, humedece a retina do olhar, mas também pelo sentimento de emanação revelada e visionária, a que as sombras e a luz da obra de Pascoaes nos eleva. A relevância da realidade na construção metafísica pascoaesiana tem, pensamos, algo de determinante e fundamental —esse algo é a própria "física", no sentido grego em geral e aristotélico em particular, já aqui referido-, pois a metafísica deixa-se descobrir na matéria, já que todos os fenómenos só o serão quando dados à análise da consciência. Nas palavras de Pascoaes, "o ser é uma síntese das coisas" imagem no espírito, a partir da sua "complexidade fenomenal".

José Marinho, um dos mais insignes hermeneutas do poeta do Marão ${ }^{4}$, definiu a metafísica como "não só e apenas o que está para além do físico, mas antes e primordialmente o que lhe é íntimo e nele se supõe" ${ }^{5}$, não se afirmando, por isso, o metafísico, por negação do físico. Muito pelo contrário, o metafísico afirma-se por apoteose do físico. Daí, em Pascoaes, a celebração da Natureza, de todo o Cosmos, no qual ele encontra o metafísico —não só nas estrelas, mas também nas montanhas, nas árvores, nas pedras.

No entanto, não se podendo classificar de um modo geral o pensamento de Pascoaes como "dialéctico", existe uma dialéctica intermitente entre o material e o imaterial, sendo o homem, e mais propriamente a sua actividade espiritual, uma síntese dessas duas vertentes. Segundo o nosso autor, o Cosmos procede num movimento de "dentro para fora", isto é, do imaterial para o material, sendo a matéria o ponto de partida para o conhecimento da essência. É a partir deste movimento que o cientista procurará a fixação do mesmo, ou, dito de outra forma, procurará estabelecer regularidades, o

\footnotetext{
${ }^{3}$ O Homem Universal, ed. cit., p. 9.

${ }^{4}$ José Marinho, discípulo de Leonardo Coimbra, foi um grande apreciador da obra de Pascoaes em particular, do seu conceito de Saudade, a respeito do qual escreveu, por exemplo, que ela "é não só musa excelsa mas deusa excelsa e gloriosa sem a qual nada se entende, nada do que para os homens é ou se fez Necessidade, nada do que se crê, se ame ou se pense como liberdade e libertação!" (in Verdade, Condição e Destino no pensamento português contemporâneo, Porto, Lello, 1976, p. 224).

${ }^{5}$ Cf. O Pensamento Filosófico de Leonardo Coimbra, Porto, Figueirinhas, 1945, p. 133.
} 
que, segundo Pascoaes, torna a visão científica necessariamente incompleta, classificando-a como "absurda", por jamais se situar numa visão fixista ou cousista, como diria Leonardo Coimbra, de um Cosmos eternamente dinâmico. Pelo contrário, só o Poeta terá a capacidade da percepção do carácter permanente activo e criador do Universo.

A essência estende-se em matéria na mesma medida em que a alma se estende em corpo, daí se podendo inferir uma relação de movimento inverso entre cosmos e conhecimento: se o primeiro procede do não material para o material, já o homem conhece a essência a partir da realidade fenoméni$\mathrm{ca}$, a partir do que ele é, do que ele sente, face à natureza e às coisas que o rodeiam, aquelas mesmas coisas que, afinal, são as sombras, que o poeta vai encher de vida, até mesmo de excesso, por representarem estas o reflexo de algo que para além delas está... Será que se pode perguntar ser possível existir Pascoaes sem aquilo que ele diz ser que não era o que é? Eis a resposta do Poeta, no poema "Canção duma sombra":

Ah, se não fosse a névoa da manhã

E a velhinha janela, onde me vou

Debruçar, para ouvir a voz das cousas,

Eu não era o que sou.

Se não fosse esta fonte, que chorava,

E como nós cantava e que secou...

E este sol, que eu comungo, de joelhos,

Eu não era o que sou.

Ah, se não fosse este luar, que chama

Os espectros à vida, e se infiltrou,

Como fluido mágico, em meu ser,

Eu não era o que sou.

E se a estrela da tarde não brilhasse;

E se não fosse o vento, que embalou

Meu coração e as nuvens, nos seus braços,

Eu não era o que sou.

Ah, se não fosse a noite misteriosa

Que meus olhos de sombras povoou,

E de vozes sombrias meus ouvidos,

Eu não era o que sou.

Sem esta terra funda e fundo rio,

Que ergue as asas e sobe, em claro voo;

Sem estes ermos montes e arvoredos,

Eu não era o que sou. 
Ora, em Pascoaes, essa celebração da natureza é, em última instância, uma filosofia da natureza. Vejamos, por exemplo, o poema Marânus:
"O que é a natureza? É qualquer cousa que não, não sendo matéria nem espírito, na sua evolução misteriosa, toma formas de espírito e matéria..."

No canto XI, ainda do mesmo poema, "Maranus, a Saudade e Dom Quixote", está presente um lirismo diáfano, ao mesmo tempo que se pressente o vivido e lembrado na memória saudosa. Diz Maranus a Quixote, no final do canto, dando também e talvez do próprio Pascoaes uma boa "definição":

"Olhando sismático a Saudade:

O meu fim é velar por esta virgem;

Santificado corpo, onde germina

A glória do meu Povo e o seu futuro,

Uma nova esperança que é divina" ${ }^{7}$

(...)

Pois tudo, tudo há-de passar, enfim,

O homem, o próprio mundo passará

Mas a Saudade é irmã da Eternidade" 8

Esta visão - da Natureza, do Mundo, do Ser-, estando presente em Maranus (1910), desenvolver-se-á também em Regresso ao Paraíso (1912). Aqui, Pascoaes fala da reconquista do Paraíso realizada pelo esforço do Homem, que é o Eterno Adão, e a sua Eva: "é da velha lembrança que nasce a nova esperança".

Poema verdadeiramente religioso, Regresso ao Paraíso foi visto, por Leonardo Coimbra, como, conforme podemos ler nas páginas d' A Águia, a "Bíblia Lusitana”, escrevendo também: "Alvorece a nova Religião, a alma portuguesa vai possuir-se em Deus". Mste sentido religioso iremos encontrá-lo, no seu clímax, na obra São Paulo, onde escreve:

“A Religião interessa-me como Revelação instintiva ou consciente (poesia pura e ciência pura); e não como regra de conduta. Deus não está nos preceitos de Moral, que é de origem social, um produto da vida em comum. Deus é, além de tudo, o Espírito criador; e o homem, antes de tudo, é o ser" $"$

\footnotetext{
${ }^{6}$ In As Sombras/ Senhora da Noitel Marânus, "Obras Completas", III, introd. e aparato crítico por Jacinto do Prado Coelho, Lisboa, Livraria Bertrand, s.d., p. 208. Cf., igualmente, mesmo no final do poema: "Mas a Saudade/ Não passará jamais e há-de ficar/ Porque ela é o Infinito, a Eternidade,/ Sobrevivente dos mundos e às estrelas".

${ }^{7}$ Ibid., p. 248.

${ }^{8}$ Ibid., p. 303.

${ }^{9}$ In São Paulo, apresentação de António Pedro de Vasconcelos, Lisboa, Assírio \& Alvim, 1984, p. 16.
} 
Por razões endógenas e exógenas, no percurso de Pascoaes sente-se a sua clara percepção relativamente às mudanças que no mundo iam acontecendo, sobretudo a partir da década de trinta, denotando, esse percurso, uma extrema coerência. Para além de todas as "voltas do mundo", para além mesmo da mudança de perspectivas - Pascoaes, a certa altura, quase deixa de escrever poesia e passa a escrever em prosa, há, de facto, essa coerência extrema. Decerto, uma coerência não estática, mas dinâmica, que foi integrando, inclusive, as maiores inovações científica da época -como, por exemplo, as que decorrem da nova física de Heisenberg, de que Pascoaes foi estando a par através do seu grande amigo e conterrâneo amarantino Ilídio Sardoreira ${ }^{10}$.

Havendo uma coerência extrema em todo o percurso de Pascoaes, em cada obra sua podemos encontrar espelhada a integralidade do seu pensamento - como, a seu ver, numa simples pedra poderíamos encontrar espelhada a integralidade de todo o Universo. Ainda assim, há decerto algumas obras que espelham, senão mais, pelo menos melhor essa integralidade do seu pensamento.

Das várias que poderíamos escolher, optámos pela sua obra "O Homem Universal”, de que iremos citar alguns excertos, ao mesmo tempo os comentando. Começamos por um excerto do primeiro capítulo:

“A vida é a morte da matéria, que se esvai, quando entre ela e o Vácuo se estabelece a menor distância. Desaparece pelos seus extremos reduzidos à mínima densidade decrescente. O mínimo menos alguma coisa é igual a nada. Atingimos o Nada, a Unidade, a Divindade. Mas temos de admitir o nada cheio de tudo, a unidade cheia de variedade, o simples muito complexo e a divindade em farrapos humanos e desumanos. Atingimos o absurdo natural, o lógico paradoxo, em que a Existência a si mesma se desvenda, por intermédio da nossa alma."11

Nesta passagem, em que se equaciona a vida à luz de dois extremos contrapolares - a matéria e o seu contrapolo extremo: "o Nada, a Unidade, a Divindade" - percebemos logo, uma vez mais, a relação entre física e metafísica, em que esta designa "não só e apenas o que está para além do físico, mas antes e primordialmente o que lhe é íntimo e nele se supõe”, para recorrermos de novo às palavras de Marinho.

No início do segundo capítulo da referida obra, observa Pascoaes o seguinte:

“A ordem é a própria força criadora ou transformadora do abstracto em concreto, do espaço em matéria, do imponderável infinito em finitos ponderáveis. Esta

${ }^{10}$ Ver, a esse respeito, "Influência do Principio de Incerteza no Pensamento de Pascoaes", in Actas do I Congresso Nacional de Filosofia, Revista Portuguesa de Filosofia, Braga, XI, 2, 1955, pp. 621-632.

${ }^{11}$ O Homem Universal, ed. cit., p. 10. 
força é o mesmo espírito divino revestindo-se de plásticos relevos inanimados e animados." 12

Pode aqui constatar-se que, se a terminologia vai variando, a ideia central permanece a mesma, isto é, a matéria nada mais é do que a cristalização do espírito e o espírito nada mais é do que a sublimação da matéria. Ou, noutros termos, o físico é a cristalização do metafísico e o metafísico a sublimação do físico. E por isso pode Pascoaes falar de "um negativo imaterial a afirmar-se materialmente" ${ }^{13}$, ou dizer-nos que "é através da matéria que o imaterial negativo se torna positivo ou animado" 14 .

Com efeito, não há no poeta-filósofo uma visão efectivamente negativa da matéria ou do físico - desde logo porque não há matéria que não esteja já entranhada de "espírito", desde logo porque não há física que não esteja já entranha de metafísica. E por isso transcende Pascoaes todas as visões dicotómicas ou maniqueístas, sempre redutoras, sempre, por isso mesmo, anti-filosóficas, por mais que se auto-intitulem "filosóficas". Não, em Pascoaes, a matéria e o espírito, a física e a metafísica, não são, de modo algum, contrários, mas, tão-só, complementares. Daí que, ainda e sempre para Pascoaes, o "homem integral" não seja apenas espiritual ou metafísico —nas suas palavras:

"O homem integral é o ser físico e metafísico, que existe desde a raiz à folha e ao perfume, se compararmos a Criação a uma árvore, a um organismo transformador de imateriais invisíveis no maravilho espectáculo das coisas! E são elas que contemplam através dos nossos olhos. Adquirem, em nós, a sua actividade espiritual, transcendente e imanente, em reflexão sobre si mesma ou sobre o panorama exterior. Esta actividade é o ponto central e crucial de todas as energias naturais - a sua unidade permanente, a alma humana." 15

Daí, também, a sua concepção de homem "artista" —aquele que se aproxima mais do seu conceito de homem "integral": "Quem não for cão pelo nariz e burro pelas orelhas, e não tiver uns olhos de andorinha, folhas e raízes de árvore, será tudo menos um artista"16-, nele se espelhando a integralidade do Universo, sobre o qual interroga e observa:

"O universo é um simples Como, sem Porquê? nem Para que? um tudo igual a uma Nada? E deste Nada igual a tudo surgiu o homem, feito de carne feroz e sombra meditativa. E o nada da sua carne feroz é o tudo da sua sombra meditativa. É imagem e espelho, mas na imagem é que a ilusão da vida se incendeia. É um retrato desenhado

\footnotetext{
${ }^{12}$ Ibid., p. 11.

${ }^{13}$ Ibid., p. 12.

${ }^{14}$ Ibid., p. 18.

${ }^{15}$ Ibid., p. 20.

${ }^{16}$ Ibid., p. 36.
} 
ou contido na sua consciente definição. Esta imagem anímica, senhora sua, apropria-se do mundo, porque o encontra dentro de si mesma, como se encontra dentro dela. A alma vive entre a matéria demoníaca e o espírito divino, entre a criação e a redenção, entre o sólido, que é a entrada na Existência, e o gasoso, que é a saída. E estando no centro das coisas, envolve-as, de longe, dispondo-as num Todo harmónico." ${ }^{17}$

Porque tudo está em tudo, "não há zero absoluto, vazio absoluto, nem Deus só Deus" ${ }^{18}$, pois o espírito está sempre já na matéria e a metafísica está sempre já na física. Na sua mais estreme materialidade, o próprio homem é sempre já um ser espiritual. Esta dimensão —a espiritual ou metafísicanão se afirma, com efeito, na negação daquela —da física ou material. Daí que a própria sexualidade humana seja em Pascoaes valorizada como "a própria substância da criatura, o seu dinamismo biológico"19, referindo-se ainda ao "corpo do desejo", à "matéria autêntica das coisas", "a encarnação do verbo, a sombra a ganhar plasticidade" ${ }^{20}$. Na medida em que reconhece tudo isso dentro si, o homem reconhece-se como "integral". Nesse limite, porém, o homem, "sendo o mundo", excede-o:

"O animal excede o vegetal, e este, o mineral. E o homem, sendo o mundo, excede o mundo, para o definir, ou abranger em pensamento. Assim, o mundo é o homem feito de terra e céu, de física e metafísica e de outros elementos ignorados, não do nosso ser, mas da nossa inteligência" ${ }^{21}$.

Mas, só mediata e precessualmente, a inteligência o descobre, aquilo que o nosso ser já sabe desde sempre, pois, como escreveu:

"o homem é, em si mesmo, neste cogito cartesiano em que ele se espiritualiza, espiritualizando ou definido o existente. O homem é a definição do Indefinido. Considera-se, portanto, um indivíduo perfeito ou acabado ou limitado; e pela mesma razão, vê o Cosmos como um Todo harmonioso, esférico, ou complexo de curvas que se fecham, guardando o maior espaço dentro delas" ${ }^{22}$.

Para Pascoaes, é o próprio homem "integral" a ponte maior entre matéria e espírito, entre física e metafísica, porquanto "dentro da existência o homem participa do mineral; e, fora dela, participa do divino" ${ }^{23}$. Daí, também, a forma como Pascoaes vê a relação entre o homem e Deus:

"O homem está separado de Deus e unido. O homem e Deus! A razão e o absurdo! Mas se Deus não fosse um absurdo, quem lhe ligaria importância ou acreditaria nele? Quem se atreveria a adorá-lo ou a negá-lo? Só amamos o absurdo e o impossível! E

\footnotetext{
${ }^{17}$ Ibid., p. 41.

${ }^{18}$ Ibid., p. 51.

${ }^{19}$ Ibid., p. 51.

${ }^{20}$ Ibid., p. 53.

${ }^{21}$ Ibid., pp. 53-54.

${ }^{22}$ Ibid., p. 57.

${ }^{23}$ Ibid., p. 64.
} 
há nisto um grande sinal. É que o impossível pode deixar de o ser... Não ignoramos os limites do possível ou todas as virtudes da matéria?”24

Como diria Agostinho da Silva, "só há homem quando se faz o impossível”. E daí, de facto, toda a tarefa do homem: realizar Deus - ou, como aqui nos diz Pascoaes, ser "a consciência da Criação e do Criador" 25 .

No homem integral se realiza a máxima harmonia entre matéria e espírito, entre física e metafísica, afirmando o nosso autor:

"No homem universal, atingem uma expressão harmoniosa os seus elementos físicos e metafísicos, o espírito e a matéria: - o espírito, essa constante na inconstância, porque ele condensa em presente duradouro e tempo volátil e concentra, em si, a Imensidade" 26

Aparecendo o homem, no Epílogo de O Homem Universal, como a "suprema expressão consciente ou sintética da Natureza" ${ }^{27}$.

Escreveu Pascoaes: "Para haver uma onda é preciso um Atlântico. E não teríamos Camões sem a Lusitânia e a Via Láctea" ${ }^{28}$. Nós acreditamos não ser possível Pascoaes, esse "fenómeno celeste", como escreveu Sant'Anna Dionísio, sem a Saudade, a Sombra e Marânus.

${ }^{24}$ Ibid., p. 65.

${ }^{25}$ Ibid., p. 76.

${ }^{26}$ Ibid., p. 99.

${ }^{27}$ Ibid., p. 113.

${ }^{28}$ Santo Agostinho (comentários), fixação do texto, introd. e notas de Pinharanda Gomes, Lisboa, Assírio \& Alvim, 1995, p. 27. 